\title{
Post-COVID 19 Syndrome: What Phenotypes can we Expect in the Clinic?
}

\author{
Editorial
}

Volume 2 Issue 3- 2021

\author{
Author Details \\ Nicolas Rodriguez-Medinaㄹ, Andrés Javier Raigoso-Loaiza², Miguel Ángel Sastoque-Pinto , Ivan David Lo- \\ zada-Martinez ${ }^{4}$ \\ ${ }^{1}$ School of Medicine, Universidad del Rosario, Bogotá, Colombia \\ ${ }^{2}$ School of Medicine, Universidad Nacional, Bogotá, Colombia \\ ${ }^{3}$ School of Medicine, Universidad Antonio Nariño, Bogotá, Colombia \\ ${ }^{4}$ School of Medicine, University of Cartagena, Cartagena, Colombia \\ *Corresponding author
}

Ivan David Lozada-Martinez, School of Medicine, Universidad de Cartagena, Cartagena, Colombia

Article History

Received: September 14, 2021 Accepted: September 24, 2021 Published: September 27, 2021

\section{Editorial}

Treatment of the acute phase and sequelae of COVID-19 remains a current challenge in medicine. With respect to sequelae, much of the evidence is limited to describing the course of this time window on average between 3 and 6 months. From such observations, it has been possible to define that there are manifestations that persist or appear some time after the acute phase of COVID-19 disease, defined as the post-COVID-19 syndrome. This syndrome is one of the major questions about the functional prognosis of this group of patients. It has been defined as the persistence or appearance of signs and/or symptoms after the acute phase of the disease, specifically in two time periods, between 4 and 12 weeks and after week 12, and potentially compromising the functional capacity of the individual [1]. It can occur in any age group and in people with or without a previous history of disease, increasing the risk of decompensation, morbidity and death [1]. Considering that the general rehabilitation process entails high health costs due to disabilities and incapacities, it is necessary to recognize and manage this syndrome at an early stage. Therefore, one of these ways is through the identification of the different phenotypes reported in the literature.

The first is post-COVID 19 tachycardic syndrome, described by Ståhlberg et al. [1], in which palpitations are present in approximately $50 \%$ of patients [1]. The causality of this phenotype is unknown, however, it has been observed that these patients also present orthostatic hypotension and findings of myocardial injury through cardiac imaging studies [1]. Urmeneta Ulloa et al. [2] carried out a study in which they evaluated 57 patients with post-COVID syndrome vs. control group through cardiac magnetic resonance imaging, evidencing that T2 mapping values (suggestive of oedema) were higher in the study patients than in the controls $(50.9 \pm 4.3 \mathrm{~ms}$ vs $48 \pm$ $1.9 \mathrm{~ms}, \mathrm{p}<0.01)$. But, no between-group differences were observed for native T1 nor for circumferential strain or radial strain values (18.6 \pm $3.3 \%$ vs $19.2 \pm 2.1 \%(\mathrm{p}=0.52)$ and $32.3 \pm 8.1 \%$ vs $33.6 \pm 7.1 \%(\mathrm{p}=0.9)$, respectively) [2]. Another very similar study, carried out by Drakos et $\mathrm{al}^{3}$, who evaluated coronary microvascular disease in COVID-19 patients by cardiovascular magnetic resonance imaging, showing that patients who had COVID-19 had significantly reduced global myocardial perfusion reserve (2.73 [2.10 - 4.15 - 11] vs. 4.82 [3.70 - 6 . $68], p=0.005)$, significantly increased coronary sinus flow at rest $(1.78$ $\mathrm{ml} / \mathrm{min}[1.19-2.23 \mathrm{ml} / \mathrm{min}]$ vs. $1.14 \mathrm{ml} / \mathrm{min}[0.91-1.32 \mathrm{ml} / \mathrm{min}], \mathrm{p}$ $=0.048)$, and reduced coronary sinus flow during stress activity $(3.33$ $\mathrm{ml} / \mathrm{min}[2.76-4.20 \mathrm{ml} / \mathrm{min}$ ] vs. $5.32 \mathrm{ml} / \mathrm{min}[3.66-5.52 \mathrm{ml} / \mathrm{min}$, $\mathrm{p}=0.05$ ), compared to controls [3]. Based on the above, the authors concluded that there is cardiac microvascular injury in COVID-19 patients, which may trigger major cardiovascular events in the postCOVID-19 phase [3]. This is probably the explanation for the postCOVID 19 tachycardic syndrome.

Pasini et $\mathrm{al}^{4}$ studied the serum blood profile of 75 patients with postCOVID syndrome, finding that all patients had very high serum concentrations of ferritin and D-Dimer. 87 and $72 \%$ of patients had clinically significant low levels of hemoglobin and albumin, respectively. Seventy three percentage had elevations in erythrocyte sedimentation rate and CRP [4]. Twenty seven percentage had elevations in $\mathrm{LDH}$, allowing the authors to conclude that these findings explain a time window of inflammatory and thromboembolic disease risk [4]. Based on these findings, we suggest the presence of a new phenotype, post-COVID 19 metabolic disorder syndrome, which can even affect any other organ with predominantly metabolic activity. 
The last is the post-COVID 19 neurological syndrome[5,6], which can occur even in patients who did not present neurological manifestations. During the process of this phenotype, cerebrovascular disorders, neuroimmune or neurometabolic disorders, derived from the neuroinflammation of the pathophysiology of COVID-19, may occur $[5,6]$. This could be the highest risk phenotype due to neurological compromise, risk of decompensation and death $[5,6]$. In this order of ideas, and based on the findings of some translational studies, we can observe how there is silent target organ injury in a large number of organs during the acute phase of COVID-19, the severity of which depends on the presence of the developed phenotype of COVID-19 and the presence of risk factors. Therefore, it is imperative to continue research on the behavior of this syndrome and the medium and longterm impact it will have on the quality of human life.

\section{References}

1. Ståhlberg M, Reistam U, Fedorowski A, Villacorta H, Horiuchi Y, Bax J, et al. (2021) Post-Covid-19 Tachycardia Syndrome: A distinct phenotype of Post-acute Covid-19 Syndrome. Am J Med 9343(21): 472-471.
2. Urmeneta Ulloa J, Martínez de Vega V, Salvador Montañés O, Álvarez Vázquez A, Sánchez-Enrique C, et al. (2021) Cardiac magnetic resonance in recovering COVID-19 patients. Feature tracking and mapping analysis to detect persistent myocardial involvement. Int J Cardiol Heart Vasc 36: 100854

3. Drakos S, Chatzantonis G, Bietenbeck M, Evers G, Schulze AB, Mohr M, et al. (2021) A cardiovascular magnetic resonance imaging-based pilot study to assess coronary microvascular disease in COVID-19 patients. Sci Rep 11(1): 15667.

4. Pasini E, Corsetti G, Romano C, Scarabelli TM, Chen-Scarabelli C, et al. (2021) Serum Metabolic Profile in Patients With Long-Covid (PASC) Syndrome: Clinical Implications. Front Med (Lausanne) 8: 714426.

5. González-Herazo MA, Silva-Muñoz DC, Guevara-Martínez PA, LozadaMartinez ID (2021) Post-COVID 19 Neurological Syndrome: a fresh challenge in neurological management. Neurol Neurochir Pol 55(4): 413-414.

6. Camargo-Martínez W, Lozada-Martínez I, Escobar-Collazos A, Navarro-Coronado A, Moscote-Salazar L, et al. (2021) Post-COVID 19 neurological syndrome: Implications for sequelae's treatment. J Clin Neurosci 88: 219-225. 